\title{
Experiment Study on Rheological Model of Soft Clay
}

\author{
Donglin Wang*, Qiuling Lv and Xiancai He
}

School of Civil Engineering, Anhui Jianzhu University, Hefei 230601, China

\begin{abstract}
This paper adopts the conventional tri-axial apparatus to respectively conduct tri-axial rheological tests on soft clay of different confining pressures by multi-stage loading vertical stress, specifically on the rheological behavior of the soft clay in Beijing area. The experimental results show that the deformation of this kind of clay has obvious time effects and nonlinear characteristics. According to the results, the test is to propose generalized Kelvin three unit and five unit model. Power function creep model and time hardening experiential models are used to describe the clay rheological behavior. The results show that, time hardening creep model is an advanced model with high accuracy, simple equations and fewer parameters and establishes a typical clay rheological model that fits Beijing area.
\end{abstract}

Keywords: Curve fitting, rheological model, rheological test, soft clay.

\section{INTRODUCTION}

Clay strain not only relates to stress levels, but also other factors, of which time effect is the most significant. This kind of time effect on stress-strain relation refers to rheological behavior, which exerts a huge influence on the long-term engineering sedimentation [1-4]. A large amount of monitoring data of Beijing subway construction illustrates that during construction, stratum and structure always set an obvious time effect on the mechanical response and this attributes to the rheological property of soft clay. There are insufficient relevant researches on the rheological behavior of the soft clay in Beijing area. So the paper takes the typical clay in Beijing area as a test object and sets up a theoretical and empirical model that best suits the clay rheological constitutive relation by adopting tri-axial test and curve fitting.

\section{TRI-AXIAL RHEOLOGICAL TEST}

\subsection{Soil Sample Preparation}

The test takes the undisturbed soft clay in Beijing area as representative soil sample, cuts it into a cylinder with a diameter of $39.1 \mathrm{~mm}$ and a height of $80 \mathrm{~mm}$. The basic physical mechanics are shown in Table $\mathbf{1}$.

\subsection{Test Method}

Prepared and saturated the soil samples indoor and carried out the tri-axial rheological test, using conventional tri-axial apparatus. Placing the samples under the same confining pressures, perform rheological tests by using multi-stage loading (adding vertical stress step by step on the same sample under a certain confining pressure).

According to field situation and relevant documents for confining pressures and loading levels, exerting confining pressures of $100 \mathrm{kPa}, 150 \mathrm{kPa}$ and $200 \mathrm{kPa}$ to soil samples $[5,6]$. According to empirical creep experiment, it makes transformation not more than $0.005 \mathrm{~mm} / \mathrm{h}$ as steady transform standard.

\section{ANALYSIS OF RHEOLOGICAL BEHAVIOR}

Based on the above experiment, rheological tests is conduct and relation curves of vertical displacement and time, void ratio and time, shear stress and shear strain are obtained. A Rheological test is taken, with a confining pressure of $200 \mathrm{kPa}$ and four-stage loading as an example, to conduct an analysis on the soil's rheological behavior.

Fig. (1) is the relation curve of vertical displacement and time under four-stage vertical pressure.

Table 1. Main physical and mechanical parameters.

\begin{tabular}{|c|c|c|c|c|c|c|}
\hline Soil sample & density/g.cm-3 & void ratio & Water content /\% & compression modulus /MPa & Internal friction angle $/^{\circ}$ & Cohesive force $/ \mathbf{k P a}$ \\
\hline \hline Soft clay & 1.99 & 0.72 & 25.2 & 7.8 & 19 & 35 \\
\hline
\end{tabular}

*Address correspondence to this author at the School of Civil Engineering,

We can see from the figure that, the creep law is rather Anhui Jianzhu University, Anhui, China; Tel: +86-13695698055;

E-mail:wdlvip@126.com similar under different stress, and has the following features: 
1) When stress level is relatively low, there is only attenuation creep period, accounting for stable creep Fig. (2).

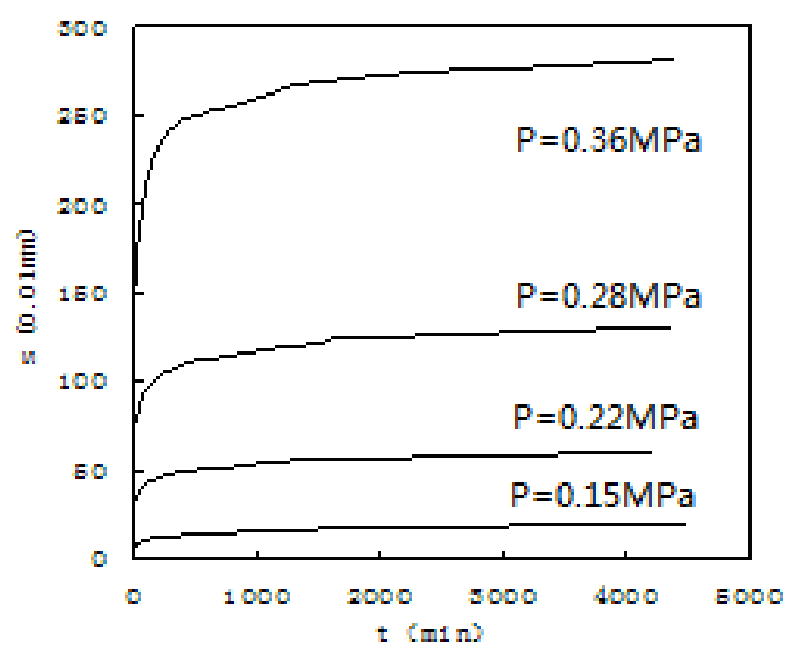

Fig. (1). Relation Curve of Vertical Displacement $s$ and Time $t$.

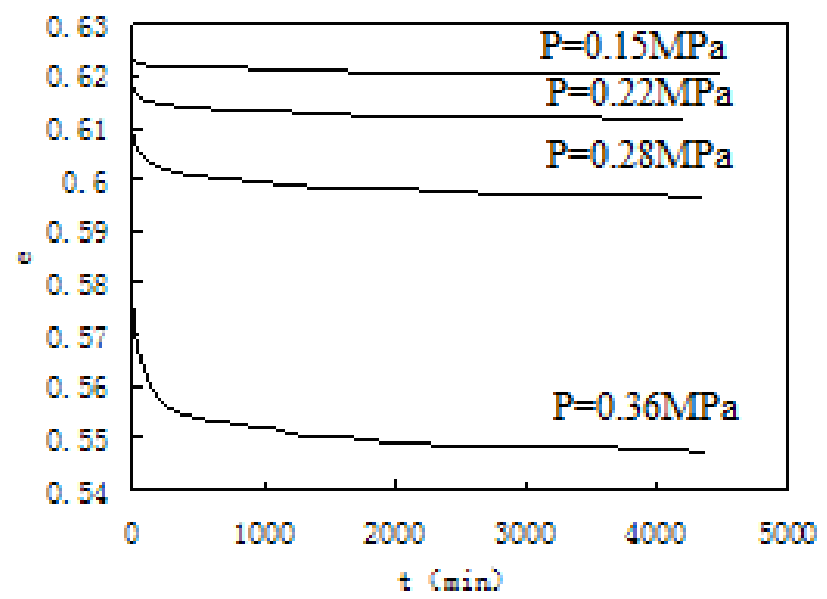

Fig. (2). Relation Curve of Void Ratio e and Time.

2) With the increase of stress level, creep deformation also increases; when stress level gets higher $\left(\sigma \geq \sigma_{s}\right)$, creep curve starts to present attenuation period and stable flow period, accounting for metastable creep.

3) When shear stress exceeds a certain limit value $\left(\sigma \geq \sigma_{p}\right.$ )creep deformation increases sharply, resulting in soil samples instability and damage, it only takes a very short time, generally several quarters, from the start to end of the period.

Fig. (3) is the relation curve of e-logt. The deformation rules of the four loading stages are clear, with a similar elogt curve of different stress levels. At each loading stage void ratio always diminishes by time. With lower stress levels, void ratio presents a linear relation with stress. The greater the stress, the faster the void ratio diminishes.

Fig. (4) is the isochronous curve of shear stress and shear strain based on Fig. (1). Seen from the figure, we know that the stress-strain relation is not a linear one under different

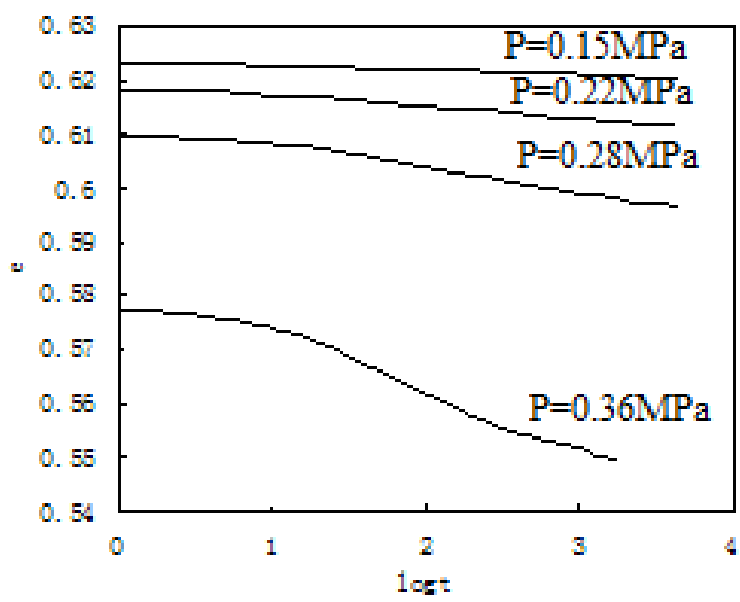

Fig. (3). Logarithmic Relation Curve of Void Ratio e and Time.

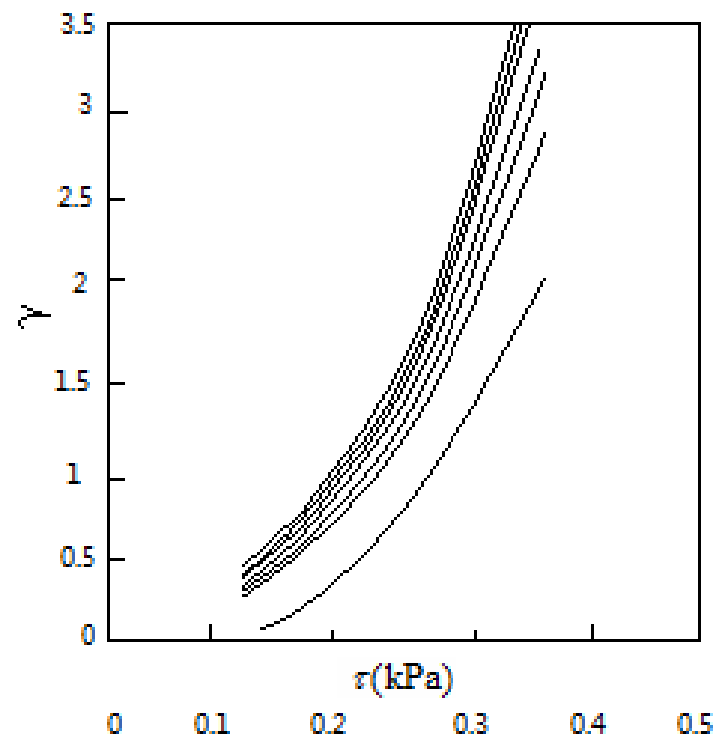

Fig. (4). Isochronous Curve of Shear Stress $\tau$ and Shear Strain $\gamma$.

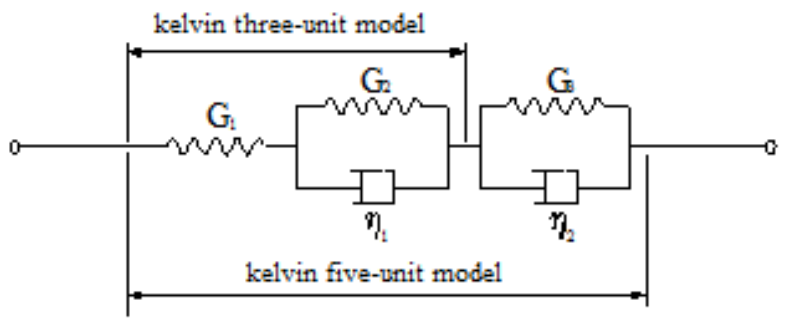

Fig. (5). Generalized Kelvin Rheological Model.

time; instead, it is a curve, which indicates that the creep deformation of the soil sample has a non-linear feature.

\section{SOIL RHEOLOGICAL MODEL}

Adopting generalized Kelvin three unit model and its extensive form five unit model as the undetermined 
theoretical rheological model Fig. (5). The test is to select power function empirical creep model and time hardening empirical creep model as undetermined empirical model. Equation of each creep model is as follows:

(1) Creep equation of generalized Kelvin three unit model is:

$\varepsilon(t)=\frac{2 \sigma_{I I}}{9 K}+\frac{\sigma_{I}}{3 G_{1}}+\frac{\sigma_{I}}{3 G_{2}}\left(1-e^{-\frac{G_{2}}{\eta_{1}} t}\right)$

(2)Creep equation of generalized Kelvin five unit model is:

$\varepsilon(t)=\frac{2 \sigma_{I I}}{9 K}+\frac{\sigma_{I}}{3 G_{1}}+\frac{\sigma_{I}}{3 G_{2}}\left(1-e^{-\frac{G_{2}}{\eta_{1}} t}\right)+\frac{\sigma_{I}}{3 G_{3}}\left(1-e^{-\frac{G_{3}}{\eta_{2}} t}\right)$

(3) Creep equation of power function empirical creep model is:

$\varepsilon(t)=A t^{n}$

(4) Creep equation of time hardening empirical creep model is:

$$
\dot{\varepsilon}^{c r}=A\left(\sigma^{c r}\right)^{n} t^{m}
$$

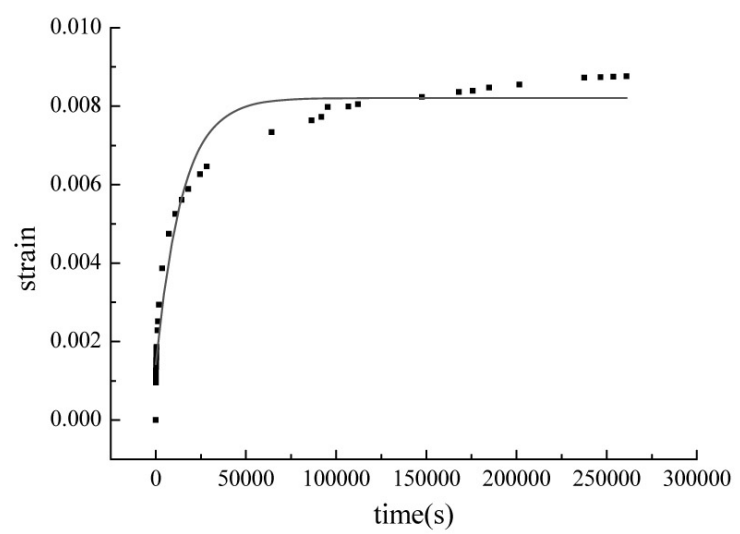

Fig. (6). Creep curve of Kelvin three-unit model.

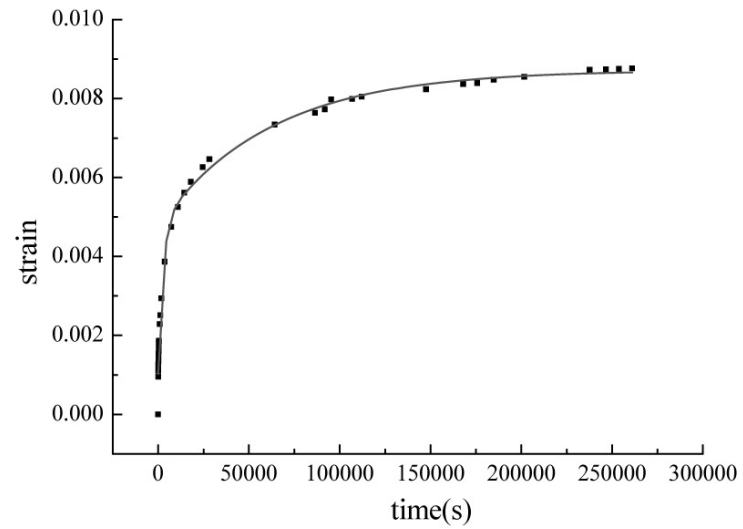

Fig. (7). Creep curve of Kelvin five-unit model.
Of the above (1) (4) formulas, $\sigma_{I}=\sigma_{1}-\sigma_{3}$ stands for deviator stress, $\sigma_{I I}=\sigma_{1}+2 \sigma_{3}$ stands for spherical stress, $\dot{\varepsilon}^{c r}$ refers to equivalent creep strain rate; $\sigma^{c r}$ refers to equivalent cohesion creep stress, $\mathrm{t}$ stands for total time, and $\boldsymbol{G}_{j}, \eta_{i}, \mathrm{~K}, \mathrm{~A}, \boldsymbol{n}$ and $\boldsymbol{m}$ are undetermined parameters.

\section{RHEOLOGICAL MODEL SELECTION}

According to the least square principle and fitting nonlinear curves based on Gauss-Newton Method, the article adopts Origin software to conduct non-linear fitting. Taking the tri-axial rheological test results under the conditions of $200 \mathrm{kPa}$ confining pressure on saturated clay and successively applying generalized Kelvin unit 3 model, unit 5 model, empirical model $\varepsilon(t)=A t^{n}$ and empirical model $\dot{\varepsilon}^{c r}=A\left(\sigma^{c r}\right)^{n} t^{m}$ Will result in the data shown in Figs. (6-9).

The fitting results show that generalized Kelvin five unit model and time hardening creep empirical model are better and their parameters are proper. The generalized Kelvin three unit ranks second with fewer parameters. While power function empirical creep model cannot correctly reflect changing rules of test data and should not be served as rheological model for the soil sample. Other confining pressure laws are similar Tables $\mathbf{2 - 5}$.

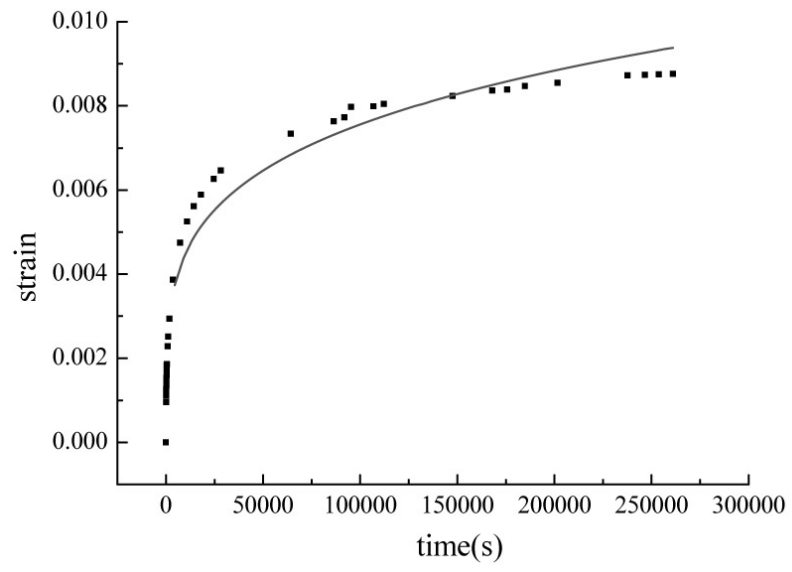

Fig. (8). Creep curve of Strain vs. time.

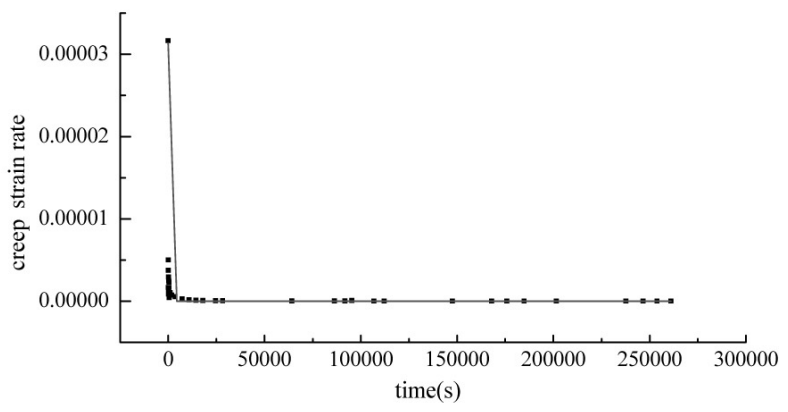

Fig. (9). Creep curve of Strain velocity vs. time. 


\section{RHEOLOGICAL MODEL SELECTION AND DATA ANALYSIS}

As time hardening empirical creep model has an easy operation and high fitting accuracy, the article only lists the test results of this model in detail.
The fitting parameters under confining pressures of 100 $\mathrm{kPa}, 150 \mathrm{kPa}$ and $200 \mathrm{kPa}$ are respectively shown in Tables 6-8 and graphicaly represented by Figs. (10-21).

Table 2. Parameters of Generalized Kelvin Three Unit Rheological Model.

\begin{tabular}{|c|c|c|c|c|}
\hline Parameter & $\mathbf{1}^{\text {st }}$ stage & $\mathbf{2}^{\text {nd }}$ stage & $\mathbf{3}^{\text {rd }}$ stage & 4.59 \\
\hline \hline $\mathrm{K}(\mathrm{MPa})$ & 4.59 & 4.59 & 0.0144 & 0.59 \\
\hline $\mathrm{G} 1(\mathrm{MPa})$ & 0.0075 & 0.0110 & 0.0082 & 0.0182 \\
\hline $\mathrm{G} 2(\mathrm{MPa})$ & 0.0043 & 0.0063 & 2.57 & 3.25 \\
\hline$\eta 1 \quad(\mathrm{MPa} \cdot \mathrm{min})$ & 1.33 & 1.97 & 0.8761 & 0.9235 \\
\hline $\mathrm{R}^{\wedge} 2$ & 0.8230 & 0.8104 & \\
\hline
\end{tabular}

Table 3. Parameters of Generalized Kelvin Five Unit Rheological Model.

\begin{tabular}{|c|c|c|c|c|}
\hline Parameter & $1^{\text {st }}$ stage & $2^{\text {nd }}$ stage & $3^{\text {rd }}$ stage & $4^{\text {th }}$ stage \\
\hline $\mathrm{K}(\mathrm{MPa})$ & 1171.4 & 171.38 & 119.20 & 89.00 \\
\hline G2（MPa） & 54.44 & 31.59 & 23.94 & 11.10 \\
\hline G3（MPa） & 41.53 & 41.10 & 25.16 & 17.22 \\
\hline$\eta 2$ (MPa.min) & 32666 & 685.7 & 1066 & 15281 \\
\hline $\mathrm{R}^{\wedge} 2$ & 0.9808 & 0.9868 & 0.9957 & 0.9990 \\
\hline
\end{tabular}

Table 4. Parameters of power function empirical creep model.

\begin{tabular}{|c|c|c|c|c|}
\hline Parameter & $\mathbf{1}^{\text {st }}$ stage & $\mathbf{2}^{\text {nd }}$ stage & $\mathbf{3}^{\text {rd }}$ stage & $\mathbf{4}^{\text {th }}$ stage \\
\hline \hline $\mathrm{A}(\mathrm{MPa})$ & 0.0092 & 0.0022 & 0.0028 & 0.0036 \\
\hline $\mathrm{n}$ & 0.0028 & 0.1103 & 0.1428 & 0.1417 \\
\hline $\mathrm{R}^{\wedge}$ & 0.1831 & 0.7862 & 0.8591 & 0.9089 \\
\hline
\end{tabular}

Table 5. Parameters of time hardening empirical creep model.

\begin{tabular}{|c|c|c|c|c|}
\hline Parameter & $\mathbf{1}^{\text {st }}$ stage & $\mathbf{2}^{\text {nd }}$ stage & $\mathbf{3}^{\text {rd }}$ stage & $\mathbf{4}^{\text {th }}$ stage \\
\hline \hline A & $1.29 \mathrm{E}-7$ & $6.72 \mathrm{E}-7$ & $2.38 \mathrm{E}-7$ & $0.99 \mathrm{E}-8$ \\
\hline $\mathrm{n}$ & 0.8936 & 1.0588 & 0.9551 & -2.0916 \\
\hline $\mathrm{m}$ & -1.7086 & -2.6859 & 0.9983 & -1.0133 \\
\hline $\mathrm{R}^{\wedge} 2$ & 0.9769 & 0.9830 & 0.9692 & 0. \\
\hline
\end{tabular}

Table 6. Time hardening model parameters $(100 \mathrm{kPa})$.

\begin{tabular}{|c|c|c|c|c|}
\hline Load value & A & $\mathbf{n}$ & $\mathbf{m}$ & $\mathbf{R 2}$ \\
\hline \hline $0.133 \mathrm{MPa}$ & $1.0184 \mathrm{E}-7$ & 0.8624 & -1.406 & 0.9859 \\
\hline $0.207 \mathrm{MPa}$ & $9.1951 \mathrm{E}-7$ & 1.0341 & -2.1166 & 0.9858 \\
\hline
\end{tabular}




\begin{tabular}{|l|l|l|l|l|}
\hline $0.282 \mathrm{MPa}$ & $6.0075 \mathrm{E}-8$ & 0.8250 & -0.8224 & 0.9826 \\
\hline $0.369 \mathrm{MPa}$ & $3.0515 \mathrm{E}-8$ & 0.8230 & -0.4698 & 0.8936 \\
\hline
\end{tabular}

Table 7. Time hardening model parameters $(100 \mathrm{kPa})$.

\begin{tabular}{|c|c|c|c|c|}
\hline Load value & $\mathbf{A}$ & $\mathbf{n}$ & $\mathbf{m}$ & $\mathbf{R 2}$ \\
\hline \hline $0.107 \mathrm{Mpa}$ & $1.8522 \mathrm{E}-7$ & 0.9052 & -1.6090 & 0.9809 \\
\hline $0.181 \mathrm{Mpa}$ & $4.5132 \mathrm{E}-7$ & 0.9837 & -1.9854 & 0.9821 \\
\hline $0.255 \mathrm{Mpa}$ & $7.1394 \mathrm{E}-8$ & 0.8435 & -1.1163 & 0.9854 \\
\hline $0.326 \mathrm{Mpa}$ & $2.0450 \mathrm{E}-8$ & 0.7868 & -0.6366 & 0.9799 \\
\hline
\end{tabular}

Table 8. Time hardening model parameters $(200 \mathrm{kPa})$.

\begin{tabular}{|c|c|c|c|c|}
\hline Load value & A & $\mathbf{n}$ & m & R2 \\
\hline \hline $0.150 \mathrm{Mpa}$ & $2.6711 \mathrm{E}-6$ & 1.1587 & -3.3784 & 0.9921 \\
\hline $0.251 \mathrm{Mpa}$ & $1.8782 \mathrm{E}-6$ & 1.1165 & -3.0387 & 0.9865 \\
\hline $0.343 \mathrm{Mpa}$ & $2.7425 \mathrm{E}-7$ & 0.9566 & -1.9618 & 0.9884 \\
\hline $0.430 \mathrm{Mpa}$ & $4.6745 \mathrm{E}-8$ & 0.8269 & -1.1254 & 0.9831 \\
\hline
\end{tabular}

\subsection{Under Confining Pressure of $100 \mathrm{kPa}$}

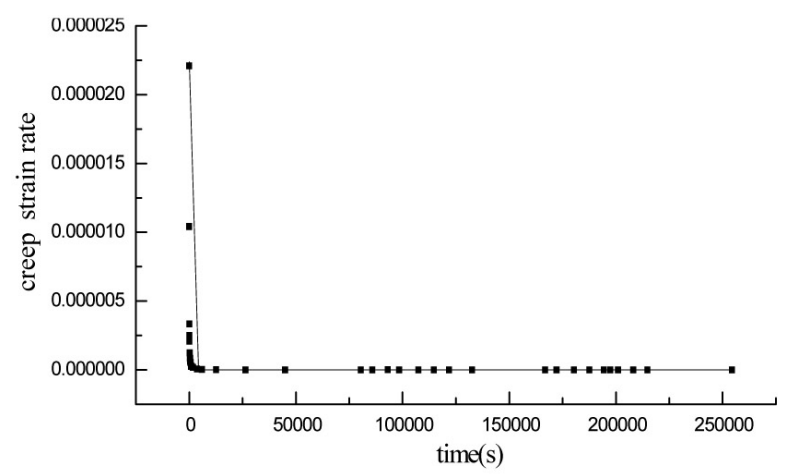

Fig. (10). Relation Curve of Strain and Time of $1^{\text {st }}$ Stage $(0.133 \mathrm{MPa})$.

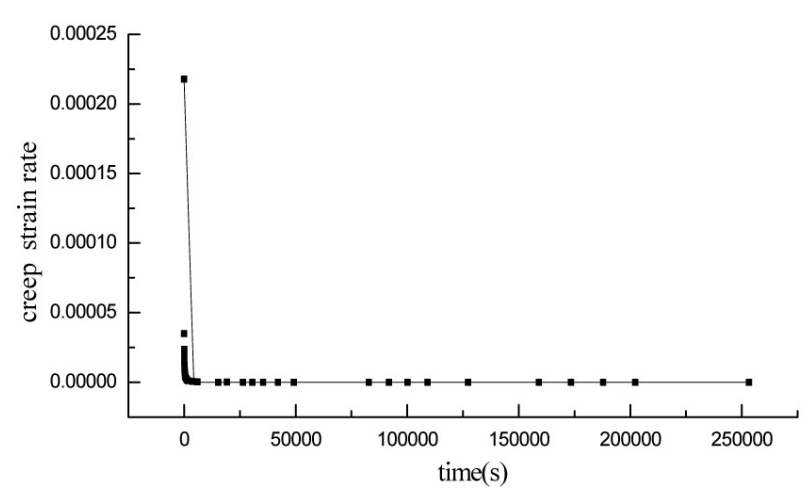

Fig. (11). Relation Curve of Strain and Time of $2^{\text {st }}$ Stage (0.207MPa).

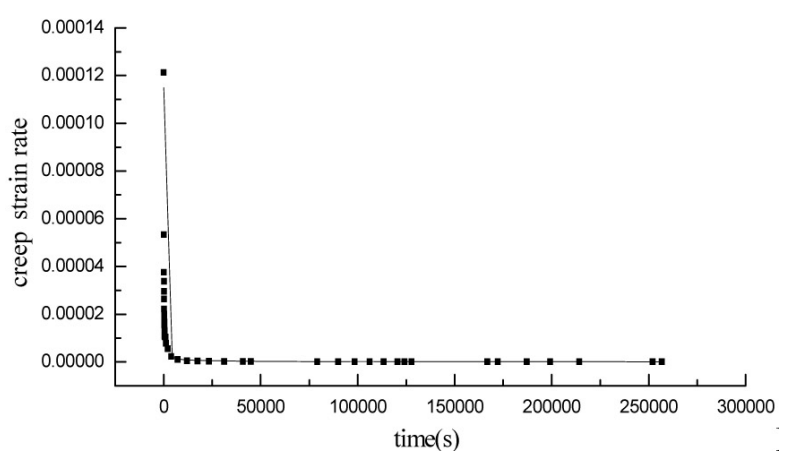

Fig. (12). Relation Curve of Strain and Time of $3^{\text {st }}$ Stage (0.282MPa).

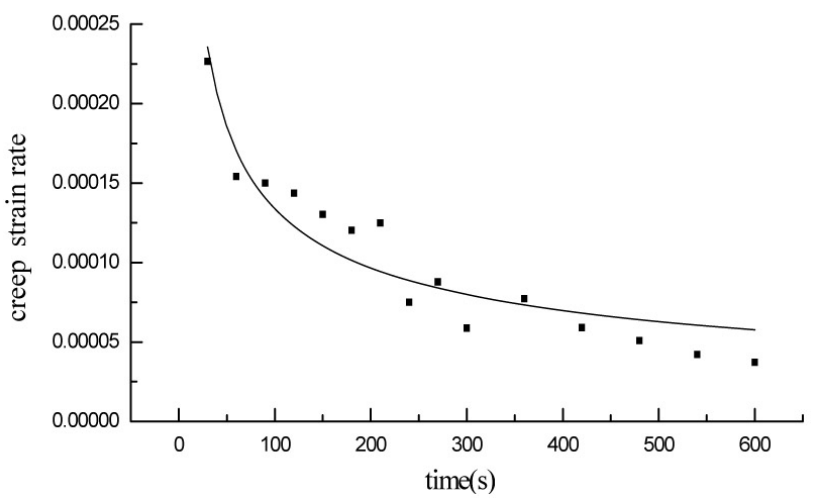

Fig. (13). Relation Curve of Strain and Time of $4^{\text {st }}$ Stage $(0.369 \mathrm{MPa})$. 


\subsection{Under Confining Pressure of $150 \mathrm{kPa}$}

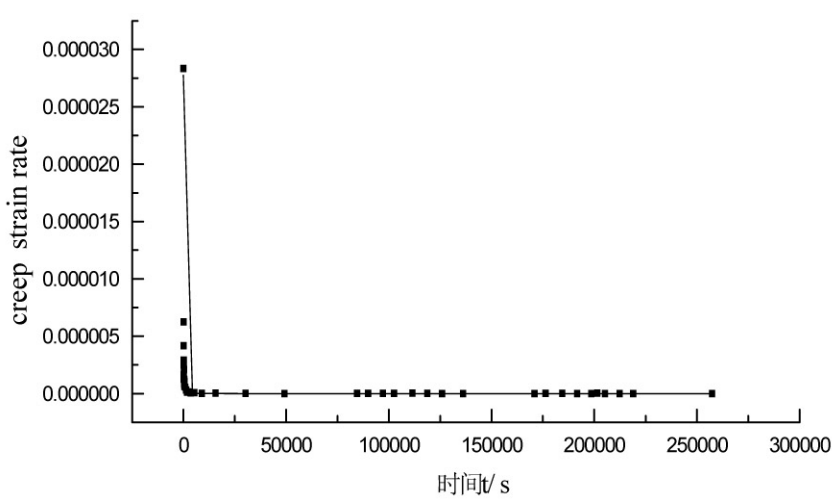

Fig. (14). Relation Curve of Strain and Time of $1^{\text {st }}$ Stage (0.107MPa).

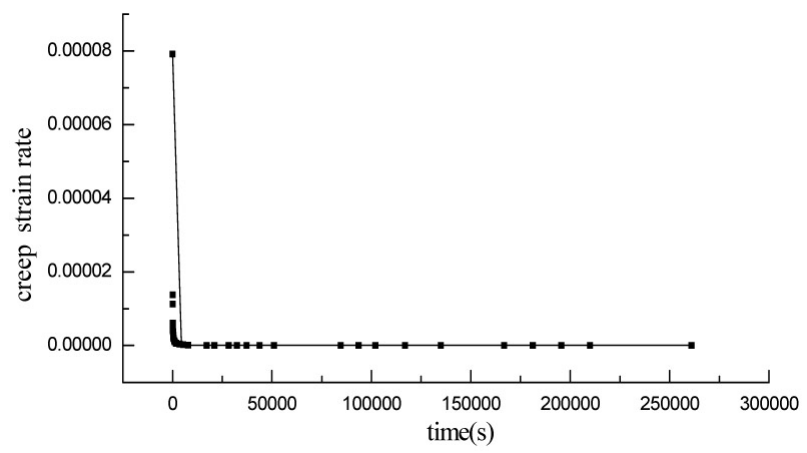

Fig. (15). Relation Curve of Strain and Time of $2^{\text {st }}$ Stage $(0.181 \mathrm{MPa})$.

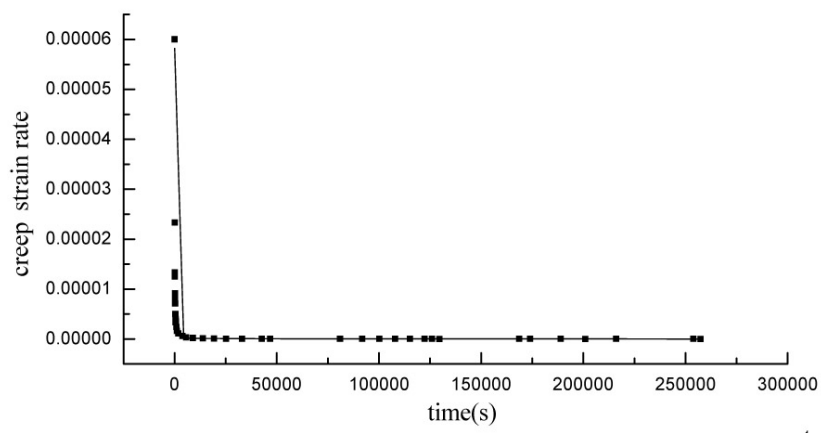

Fig. (16). Relation Curve of Strain and Time of $3^{\text {st }}$ Stage (0.255MPa).

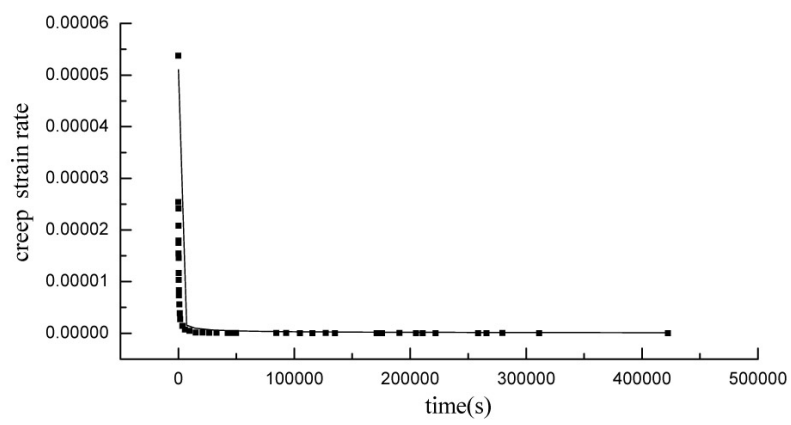

Fig. (17). Relation Curve of Strain and Time of $4^{\text {st }}$ Stage $(0.326 \mathrm{MPa})$.

\subsection{Under Confining Pressure of $200 \mathrm{kPa}$}

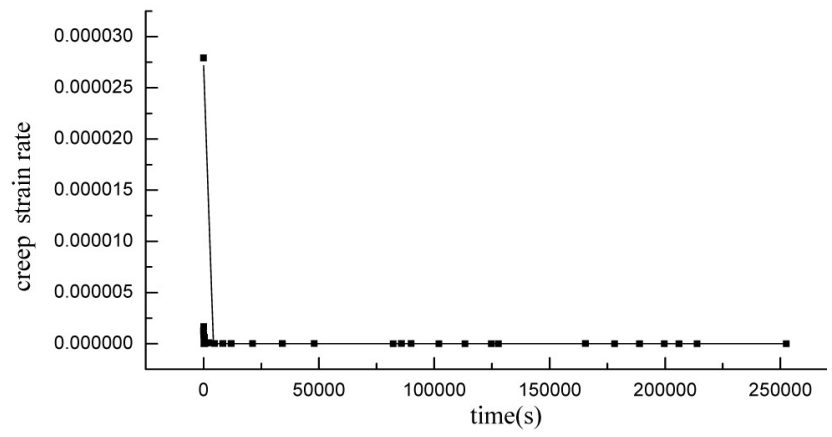

Fig. (18). Relation Curve of Strain and Time of $1^{\text {st }}$ Stage (0.150MPa).

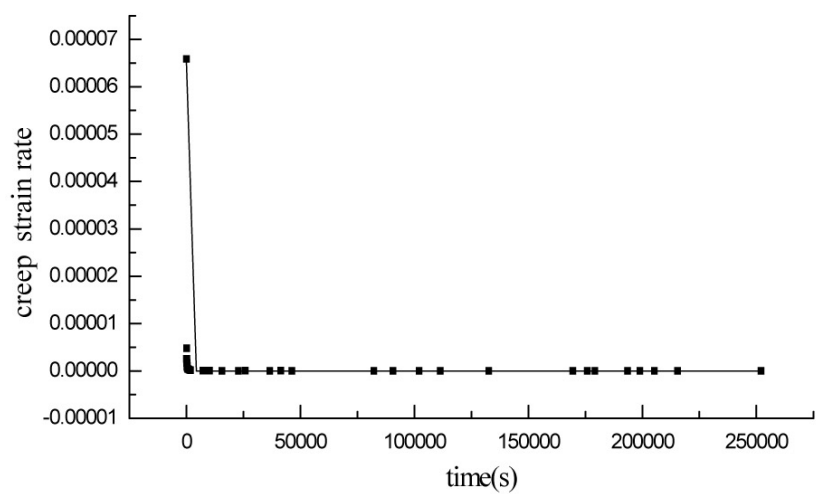

Fig. (19). Relation Curve of Strain and Time of $2^{\text {st }}$ Stage $(0.251 \mathrm{MPa})$

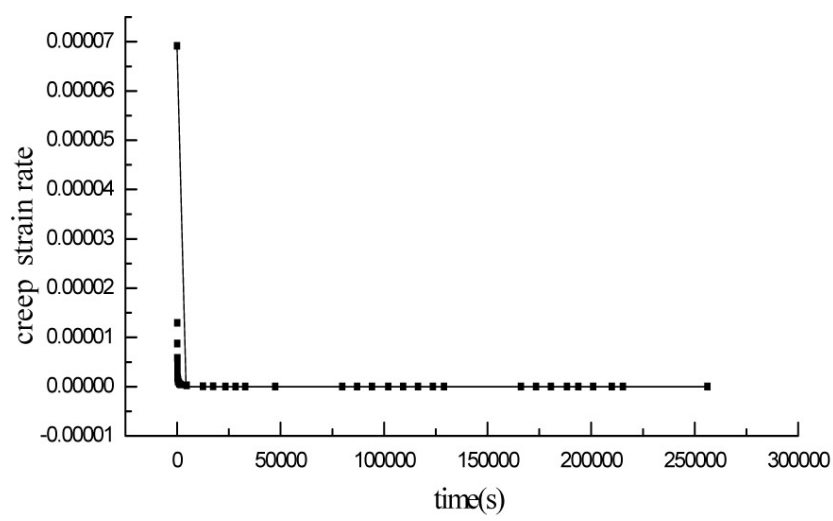

Fig. (20). Relation Curve of Strain and Time of $3^{\text {st }}$ Stage (0.48134MPa).

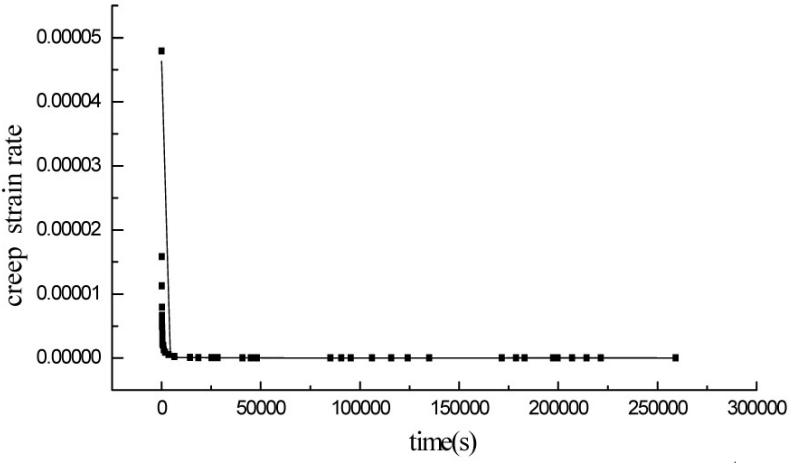

Fig. (21). Relation Curve of Strain and Time of $2^{\text {st }}$ Stage $(0.251 \mathrm{MPa})$. 


\section{CONCLUSION}

Through indoor tri-axial rheological test, the article has made a research on the rheological behavior of typical saturated clay in Beijing area in detail and has drawn the following conclusions:

(1) The typical saturated clay in Beijing area has obvious rheological properties which cannot be ignored in soil deformation analysis.

(2) For generalized Kelvin unit 3 or unit 5 models, under the same confining pressure $(\sigma 3)$, with the increase of vertical load $(\sigma 1)$, shear modulus $(\mathrm{G} 1, \mathrm{G} 2$ and G3) and viscosity parameters $(\eta 1, \eta 2$ and $\eta 3)$ of one sample are generally decreasing; the result indicates that, as vertical load $(\sigma 1)$ increases, material anti-deformation capability decreases, and deformation accelerates.

(3) For generalized Kelvin unit 3 or unit 5 models, with the increase of confining pressure $(\sigma 3)$, shear modulus $(\mathrm{G} 1$, $\mathrm{G} 2$ and G3) and viscosity parameters $(\eta 1, \eta 2$ and $\eta 3)$ of one sample are generally increasing. The result indicates that, as confining pressure $(\sigma 3)$ increases, material antideformation capability increases, and deformation decelerates.

(4) When adopting empirical models to describe creep behaviors, time hardening empirical creep model is more accurate than power function empirical creep model and can describe deformation more precisely. Time hardening empirical creep model has been widely used due to its high-accuracy, easy rheological equation and fewer parameters.

\section{CONFLICT OF INTEREST}

The authors confirm that this article content has no conflict of interest.

\section{ACKNOWLEDGEMENTS}

The paper is funded by the Natural Science Foundation of Anhui Province, China (1308085QE85).

\section{REFERENCES}

[1] J. S. Li, Y. M. Lin, "Singh-mitchell creep model of Shanghai very soft silt clay", Rock Soil Mech., vol. 21, no. 4, pp. 363-366, 2000.

[2] Y. J. Chen, C. L. Pan, P. Cao, W. X. Wang, "A new mechanical model for soft rock rheology", Rock Soil Mech., vol. 24, no. 2, pp. 209-214, 2003

[3] J. H. Zhang, L. C. Miao, "Tests on rheological behavior of lianyungang marine soft clay and two yield-surface rheological mode", Rock Soil Mech., vol. 26, no. 1, pp. 145-149, 2005.

[4] H. Hu, "Rheological model and rheological equation of sullage soft soil under dynamic loading", Rock Soil Mech., vol. 28, no. 2, pp. 237-240, 2007.

[5] Y. Shao, C. H. Yan, B. T. Xu, "Identification on rheological model of lacustrine soft soil and its engineering application", Rock Soil Mech., vol. 33, no. 8, pp. 2384-2387, 2012.

[6] M. H. Zhao, Y. Xiao, C. F. Chen, "Laboratory experiment of the rheological property of soft clay and improved xiyuan model", $J$. Hunan Univ. (Nat. Sci.), vol. 31, no. 1, pp. 48-51, 2004

(C) Wang et al.; Licensee Bentham Open.

This is an open access article licensed under the terms of the Creative Commons Attribution Non-Commercial License (http://creativecommons.org/licenses/by-nc/3.0/) which permits unrestricted, non-commercial use, distribution and reproduction in any medium, provided the work is properly cited. 